\title{
Shame on who? The effects of corporate irresponsibility and social performance on organizational reputation
}

Article

Accepted Version

Nardella, G., Brammer, S. and Surdu, I. (2020) Shame on who? The effects of corporate irresponsibility and social performance on organizational reputation. British Journal of Management, 31 (1). pp. 5-23. ISSN 1467-8551 doi: https://doi.org/10.1111/1467-8551.12365 Available at https://centaur.reading.ac.uk/83162/

It is advisable to refer to the publisher's version if you intend to cite from the work. See Guidance on citing.

To link to this article DOI: http://dx.doi.org/10.1111/1467-8551.12365

Publisher: Wiley

All outputs in CentAUR are protected by Intellectual Property Rights law, including copyright law. Copyright and IPR is retained by the creators or other copyright holders. Terms and conditions for use of this material are defined in the End User Agreement.

www.reading.ac.uk/centaur 
Central Archive at the University of Reading

Reading's research outputs online 


\title{
Shame on who? The Effects of Corporate Irresponsibility and Social Performance on Organizational Reputation
}

\begin{abstract}
This study examines the relationship between corporate irresponsibility, corporate social performance and changes in organizational reputation. By combining attribution theory with expectancy violations theory, we provide the first systematic analysis of how organizational reputations are influenced by attributions of corporate irresponsibility in the context of social expectations. Drawing on a comprehensive and unique corporate irresponsibility dataset, this study reveals that firms previously believed to be most socially responsible are penalized by evaluators when corporate culpability is verified by a court of law. Conversely, firms perceived as least socially responsible were more likely to suffer reputation penalties when accused of irresponsibility, without their culpability established through litigation. Overall, the results of our study suggest that organizational reputations are mostly stable in light of irresponsibility, in that evaluators only penalize certain firms, in certain circumstances. Specifically, reputation penalties occur when highly responsible firms are perceived hypocritical and least responsible firms were not found culpable by a court of law. Upon reflection of these findings, our study reveals that the mechanisms of social sanction previously assumed to regulate irresponsibility are weaker than currently understood. Theoretical and policy implications of this study are discussed, along with directions for future research on social evaluations.
\end{abstract}

\section{Introduction}

Meeting stakeholder expectations is widely viewed as an important driver of organizational success. To achieve this, many organizations espouse pro-social values (Aguilera, Rupp, Williams and Ganapathi, 2007) and allocate resources to achieve socially-oriented objectives 
(Margolis and Walsh, 2003). In doing so, organizations may achieve enhanced corporate social performance (CSP) and be perceived favourably (Barnett and Salomon, 2012; Brammer and Millington, 2004). Yet these same organizations are often observed behaving irresponsibly. Corporate irresponsibility (CI hereafter) may generate substantial unwanted stakeholder attention on firms (Campbell, 2007; Deephouse and Heugens, 2009) because when revealed, CI - organizational behaviors which are perceived to be egregious by observers (Lange and Washburn, 2012) - can damage organizational reputations (Karpoff and Lott 1993; Mishina, Block and Mannor, 2012).

Thus far, CI research lacks consensus vis-à-vis the effects of irresponsibility on organizational reputation, with one strand of research arguing that irresponsibility is generally detrimental to stakeholder evaluations of the firm (He, Pittman and Rui, 2016; Kölbel, Busch and Jancso, 2017; Sweetin, Knowles, Summey and McQueen, 2013) and another proposing that irresponsible conduct can result in varying reputational effects (Love, Lim and Bednar, 2017; Oikonomou, Brooks and Pavelin, 2014; Zyglidopoulos, 2001). To explain variation in reputational effects of $\mathrm{CI}$, some scholars suggest that individuals differ in their views on what constitutes irresponsible conduct (Antonetti and Anesa, 2017; Lange and Washburn, 2012; Reinecke and Ansari, 2016). From this perspective, alterations in stakeholder perceptions are the consequence of moral judgements, rather than objective breaches of social standards. However, empirical research has yet to examine how the heterogeneity and complexity of CI events are interpreted, and responded to, by organizational assessors. Recognizing the heterogeneity of CI events is important because the characteristics that distinguish events to assessors, such as CI being associated with undesirable outcomes, non-complicit stakeholder groups, or clear evidence that the firm had, indeed, acted irresponsibly, may present different risks to reputation. We propose that, attribution theory (Lange and Washburn, 2012), with its 
focus on how the characteristics of events are interpreted by social assessors, represents a promising line of research to empirically examine the heterogeneity of CI.

Furthermore, stakeholders' prior expectations of the organization may play a role in shaping perceptions (Rhee and Haunschild, 2006). "Kindergarten ethics" suggests that negative behavior is typical of irresponsible actors and positive behavior is typical of responsible actors (Lessig, 2013: 553). However, moral judgements, in reality, are more complex. Firms simultaneously engage in corporate social responsibility activities, whilst also being observed to behave irresponsibly. From an expectancy violations perspective (Burgoon, 1978: Bailey and Bonifield, 2010), firms with a history of positive social performance may be held to higher standards of behavior than firms with low social performance. We propose that, the characteristics of a CI event, as well as prior stakeholder expectations of the organization, may provide important contextual information for reputation assessments.

This paper addresses the following research question: to what extent are organizational reputations influenced by CI in the context of a firm's prior CSP? Despite the prevalence of CSR and CI as business phenomena "we lack research that helps us locate the fine line dividing the tendency of audiences to disregard events that contradict current perceptions and their willingness to reconsider their judgments and form new and different evaluations of organizations" (Ravasi, Rindova, Etter and Cornelissen, 2018: 585). Our research attends to this gap by examining when, how and for whom social evaluations of irresponsibility lead to changes in organizational reputation. We propose that stakeholder perceptions of irresponsible events and the firm's level of prior social performance drive stakeholders to revise organizational reputation in light of CI. Our rationale is that, corporate hypocrisy - the inconsistent behavior which involves claiming higher values or standards than is the case (Wagner et al., 2009) - may be penalized most severely when CI contradicts an organization's pro-social claims. This means that firms with higher CSP may be more at risk to be seen as 
hypocritical in light of CI. Conversely, firms with low CSP are unlikely to violate stakeholder expectations to such an extent.

To study the determinants of reputational change, this paper combines attribution theory with expectancy violations theory. Attribution theory, rooted in social psychology (Kelley, 1967; Weiner, Graham and Chandler, 1982), focuses on the underlying characteristics of events most salient to stakeholders. From an attribution theory perspective, situational characteristics of CI such as assessments of whether the firm is culpable for the event, the presence of victimized party non-complicity and the effect undesirability of a CI event, influence social evaluations of the firm (Lange and Washburn, 2012). Expectancy violations theory complements this view by suggesting that CI evaluations are also shaped by prior expectations of the firm, such as prior social performance (Rhee and Haunschild, 2006; Zavyalova, Pfarrer, Reger and Hubbard, 2016).

This paper makes three main contributions. The paper provides the first systematic, large-scale empirical examination of the effect of CI attributions on changes in organizational reputation. Second, by combining attribution theory with expectancy violations theory, we advance our understanding of how stakeholder assessments are actually formulated, namely as a result of perceptions of organizational behavior informed by prior expectations of the firm. Third, using a multi-theoretical lens, we explore the contextual conditions that provoke changes in organizational reputation. Most notably, we reveal for whom situational characteristics of irresponsibility lead to alterations in stakeholder evaluations, namely CI for the top and bottom social performers.

The remainder of this paper proceeds as follows. First, we draw on attribution theory to explain which aspects of CI are most relevant to stakeholders' social evaluations. Then, we discuss how expectancy violations theory complements this view by providing an understanding of how firm-specific contextual factors moderate stakeholder evaluations of CI. 
Next, we proceed with our hypotheses. We subsequently outline our methodology and results. Finally, we discuss the theoretical and policy implications of our findings and provide future research recommendations.

\section{Theoretical Development}

\section{Attribution theory}

From an attribution theory perspective, social evaluations of the firm are the outcome of individual perceptions. General, widely accepted evaluations of the firm are influenced by the subjective, biased and potentially flawed interpretations of individuals, as well as their capacity for objective reasoning (see Sjovall and Talk, 2004). In this way, individual perceptions create the social reality where an organization can fall victim to negative social revaluations (Bitektine, 2011; Fombrun and Rindova, 1996; Mishina et al., 2012). Attribution theory, developed in social psychology (Kelley, 1967; Weiner et al., 1982), places the interpretations of the individual in a position of central significance to the social evaluations process (Lange and Washburn, 2012). Attribution theory can be used to outline the characteristics of CI which provide salient cues for social evaluations.

Although social evaluations are not assessed against a widely agreed upon, objective standard (Skilton and Purdy, 2017), the management literature has proposed that three situational characteristics of CI are significant in shaping stakeholder perceptions, and subsequent evaluations of the firm (Haidt and Bjorklund, 2008; Lange and Washburn, 2012; Leavitt, Zhu and Aquino, 2016). First, the certainty with which CI's causality can be inferred may influence social evaluations. In circumstances where few alternative causal inferences can be drawn, stakeholder scrutiny may be placed solely on the accused and its activities (Kelley, 1972; Walker, Heere, Parent and Drane, 2010). Because causal attributions are not necessarily based on an objective reality, perceptions can be rooted in, for instance, an individual's intuition 
(see Bailey and Bonifield, 2010); hence, evaluations of corporate culpability may vary (Walker et al., 2010). Implicitly, stakeholders are expected to navigate ambiguous information to identify plausible explanations for events (Yoon, Gürhan-Canli and Schwartz, 2006). Research has suggested that corporate culpability is an important factor in determining the reputation penalties associated with CI (Claeys, Cauberghe and Vyncke, 2010; Coombs and Holladay, 2006; Laufer and Coombs, 2006). However, research on corporate culpability has yet to explore the cues associated with 'real-life' cases of CI, where culpability may be ambiguous in some instances or determined by a court of law in others.

A second characteristic of CI proposed by the management literature describes the relationship that victimized parties have to the organization (Lange and Washburn, 2012). Stakeholders victimized by CI may act as cues for social evaluations, i.e. assessors may perceive some stakeholders more complicit in CI events than others (Alicke, 2000). Social evaluators may subsequently estimate the degree to which the affected parties were complicit in the event, in order to determine the degree of sympathy deserved (Leavitt et al., 2016). For example, the shareholders of former UK bank, Northern Rock, may have garnered less sympathy from stakeholders after the 2008 financial crisis, as they may have been perceived as complicit in the bank's investments. Contrastingly, the customers of Northern Rock may have been met with greater sympathy, for they did not benefit from the bank's behavior to such an extent. When the victims of CI are perceived to be non-complicit, increased sympathy is elicited. However, to date, research has yet to explore empirically whether stakeholder perceptions of victimized party non-complicity for CI translate into changes in organizational reputation.

The third situational characteristic outlined by attribution theory proponents as central to social evaluations is the degree to which a CI event is perceived to have undesirable effects. Stakeholder calculations of what is referred to as effect undesirability (Lange and Washburn, 
2012), may be influenced by whether or not an event elicits an emotional response; e.g. when an incident is considered as personally threatening to the evaluator or their own values and belief systems (Donaldson and Dunfee, 1999; Haidt and Bjorklund, 2008). Evaluators may then enter a state of increased alertness that increases information-searching behavior and may even increase criticality towards the firm (Weick, Sutcliffe and Obstfeld, 2005). Effect undesirability reflects that perceptions of CI events depend, at least to some extent, on the stakeholders' subjective calculations of the severity of CI effects. Following this rationale, negative perceptions of effects undesirability may increase stakeholder scrutiny. However, to date, research has yet to explore perceptions of effect undesirability and its influence on organizational reputation. In this study, attribution theory represents an opportunity to enhance our understanding of the individual as well as combined influence of; corporate culpability, affected party non-complicity and effect undesirability on changes in organizational reputation.

\section{Expectancy Violations Theory}

The past actions of the firm, both positive and negative, can also provide important contextual information for social evaluations of the firm (Wei, Ouyang and Chen, 2017). From an expectancy violations perspective, CI may reflect greater risks to reputation for some organizations, than for others (Vanhamme and Grobben, 2009). CI's violation of stakeholder expectations may depend largely on what stakeholders' expectations of the firm were prior to the CI event. Firms may therefore vary in their level of social approval (Bundy and Pfarrer, 2015), where stakeholders may commend a firm's social performance or disapprove of that firm's behavior, thus building either greater or reduced expectations around the firm's future conduct. Following this rationale, the social evaluations of CI may be shaped by organizational assessors' prior expectations (Mishina et al., 2012). 
Research from the strategic management and corporate social responsibility perspectives suggest that a good reputation provides organizations with a form of 'insurance' that may offset the associated reputational risks of CI (Brammer and Pavelin, 2005; Ducassy, 2013; Godfrey, 2005; Janney and Gove, 2011; Minor and Morgan, 2011). Expectancy violations research, in contrast, suggests that positive expectations can also create greater risks to reputation (Burgoon, 1978; Rhee and Haunschild, 2006) when the firm's behavior is perceived as irresponsible. Instances where expectations of the firm are violated, prompt stakeholders to revise-down their assessments of the organization in light of CI. Expectancy violations theory suggests that firms previously perceived as being highly socially responsible are more harshly punished by stakeholders for irresponsible behavior than firms with weaker prior social performance (Price and Sun, 2017; Yoon et al., 2006). This is particularly the case when irresponsible behavior contradicts stakeholder beliefs regarding the core values, capabilities and/or characteristics of the firm. For instance, firms believed to be well governed, may be perceived as hypocritical when irresponsible governance is revealed (Janney and Gove, 2011).

Overall, the conditions that elicit negative social evaluations are under-studied (Ravasi et al., 2018). We propose that, when firm characteristics such as a firm's level of CSP are explored in conjunction with CI, they will unveil more nuanced stakeholder assessments at work. We combine attribution theory rationales with the expectancy violations perspective to examine the effects of CI and CSP on changes in reputation. We investigate the differing reputational effects of irresponsibility for firms with relatively higher levels of prior CSP compared to firms with low CSP.

\section{Hypothesis Development}


Stakeholder assessments of irresponsible corporate conduct require value judgements to be made (Marín, Cuestas and Román, 2015). In line with attribution theory proponents (Lange and Washburn, 2012), we also argue that the situational characteristics of CI provide the most salient cues to stakeholders, who in turn interpret these characteristics and calculate their moral significance (Appiah, 2009). This means that, without the presence of evidence to inform stakeholders that there is indeed, corporate culpability, non-complicit victims and/or undesirable outcomes, it is unlikely that stakeholders will respond emotively to CI. In turn, CI events where corporate culpability is unambiguous, cues that suggest that the CI event victimizes vulnerable, non-complicit stakeholders, and CI events that are associated with highly undesirable outcomes, are salient to stakeholder assessments. Salient and highly emotive stimuli such as these may elicit significant emotional responses from stakeholders (Loewenstein, 1996) which may subsequently lead to changes in organizational reputation.

Further, we add that without perceptions that the firm had, indeed, behaved irresponsibly, i.e. there is no significant evidence of culpability, affected party non-complicity and/or effect undesirability, we would not expect changes in reputation. Without irresponsibility being perceived as such, we also have no basis to assume that there will be changes in reputation for firms with highest CSP scores compared to those with relatively low CSP. Our baseline proposition is that organizational assessors are not motivated to revaluate organizational reputation without sufficient evidence of corporate culpability, harm to noncomplicit parties or undesirable effects of CI. Hence, our first hypothesis is as follows:

H1: Ceteris paribus, the occurrence of CI alone will not have a significant relationship with changes in reputation. 
In turn, we expect stakeholders' interpretations of CI events and firms' past CSP to influence changes in firms' reputations. Stakeholders may expect particularly considered, ethical behaviors from highly responsible firms (Janssen, Sen and Bhattacharya, 2015; Mishina et al., 2012). This means that organizational assessors may be also motivated to revise-down the reputations of firms with enhanced CSP after revelations of irresponsibility (Janney and Gove, 2011). In these circumstances, CI becomes inconsistent with prior social evaluations of the firm, provoking perceptions of betrayal and hypocrisy (Wagner et al., 2009). When organizations are perceived to be hypocritical, assessors may re-evaluate whether their reputations were ever justified. In contrast, firms who are already known to have low social performance, are less likely to provoke perceptions of hypocrisy (Price and Sun, 2017), in which case, low CSP firms may not breach stakeholder expectations to the same extent as higher CSP firms (Carlos and Lewis, 2018; Kim, 2014). For instance, consumer deception may be more significant to reputation for the Volkswagen Group (Germany) than for Nestlé (Switzerland), with the latter being known to underperform with regards to its social responsibilities (Tucker and Melewar, 2005). Irresponsibility can therefore be viewed as consistent with low CSP firm behavior. Thus, CI may not elicit strong negative emotional responses from stakeholders who will, to some extent, be unsurprised to learn of irresponsibility from low social performers.

Because firms with relatively higher levels of prior social performance provoke perceptions of hypocrisy when CI reveals either unambiguous corporate culpability, or harm to non-complicit parties, or undesirable outcomes, these firms may be associated with greater negative changes in their reputation. Conversely, CI may be associated with relatively lower negative changes in reputation for firms with lower CSP, for whom stakeholder expectations are already reduced. We hypothesise that: 
H2a: CI where the firm is found culpable will have a negative relationship with changes in reputation and this effect is greater (weaker) for firms with higher (lower) levels of CSP.

$H 2 b$ : CI where a non-complicit party is victimized will have a negative relationship with changes in reputation and this effect is greater (weaker) for firms with higher (lower) levels of CSP.

$H 2 c$ : CI where the effect of the event is undesirable will have a negative relationship with changes in reputation and this effect is greater (weaker) for firms with higher (lower) levels of CSP.

Furthermore, the context surrounding CI events also varies. Some events reveal unambiguous corporate culpability, harm to non-complicit parties as well as being associated with undesirable outcomes (Lange and Washburn, 2012). Other CI events reveal evidence of only some of these. CI may, for example, only reveal culpability for an event, yet the event may not be associated with any significant effect undesirability or harm to non-complicit parties. Because social evaluations are not always considered objectively by assessors (Antonetti and Maklan, 2016; Grappi, Romani and Bagozzi, 2013; Voliotis, Vlachos and Epitropaki, 2016), CI with multiple situational characteristics - namely combinations of unambiguous culpability, the presence of non-complicit vulnerable parties and significant effect undesirability - may amplify the severity of irresponsibility perceptions than evidence of only one of these characteristics. Building on prior research, we propose that the presence of multiple situational characteristics of CI elicits greater emotional responses from stakeholders (Lange and Washburn, 2012). More stakeholder attention and scrutiny may be drawn to these events (Fiske and Taylor, 1991). For instance, being associated with child labour (affected party noncomplicity) may be a lesser risk to reputation than being found guilty for child labour by a court of law (culpability). When strong evidence of CI (i.e. multiple situational characteristics) exists, organizational assessors may become more convinced that the firm has, indeed, behaved 
irresponsibly. We propose that, when multiple situational characteristics of CI are present, changes in organizational reputation are more significant than when evidence of only one of these characteristics is revealed.

In this case also, we argue that perceptions of CI will be shaped by stakeholder prior expectations. When firms are held to a higher standard by organizational assessors, significant evidence of CI will jar even more strongly with expectations of the firm (Rim, Park and Song, 2018), which is then perceived as hypocritical. Corporate hypocrisy, we argue, will provoke negative alterations in organizational reputation for CI with multiple situational characteristics as follows:

H3a: CI where there is culpability and affected party-non-complicity has a stronger negative relationship with changes in reputation than CI with one event characteristic and this effect is greater for firms with relatively higher CSP.

$H 3 b$ : CI where there is affected party-non-complicity and effect undesirability has a stronger negative relationship with changes in reputation than CI with one event characteristic and this effect is greater for firms with relatively higher CSP.

H3c: CI where there is culpability and effect undesirability has a stronger negative relationship with changes in reputation than CI with one event characteristic and this effect is greater for firms with relatively higher CSP.

Finally, accusations of CI may represent the most salient stimuli to organizational assessors when significant evidence of all three situational characteristics are present (Lange and Washburn, 2012). The combination of unambiguous corporate culpability, harm to noncomplicit parties, and highly undesirable CI outcomes prompt the attention of both the media and stakeholders most significantly, as these events signal highly newsworthy (Carroll and McCombs, 2003) and severe organizational behavior (Lange and Washburn, 2012). These 
instances are therefore likely to create the most heightened, negative emotional response from stakeholders (Grappi et al., 2013). Examples where significant evidence of these three situational characteristics was followed by reputational penalties include the racial discrimination at General Electric (USA), Nestlé's (Switzerland) infant formula scandal and the BP (UK) Deepwater Horizon oil spill. Furthermore, amongst these three examples, BP was seemingly the company with the most significant reputational decline. This corresponds to previous efforts by BP to substantially increase their social performance. This is aligned with our proposition that, for firms with highest CSP, irresponsibility events with significant evidence of all three situational characteristics are most threatening to reputation because they best represent the conditions that are understood to provoke attributions of irresponsibility (Lange and Washburn, 2012) and social evaluations of hypocrisy (Wagner et al., 2009). Whilst such CI events also represent reputationally threatening contexts for firms with low CSP, we propose that, the degree to which CI evokes emotional responses in stakeholders is lessened due to a-priori lower stakeholder expectations. Therefore, our final hypothesis states that:

H4: CI where the firm is simultaneously found culpable AND a non-complicit party is victimized, AND the effect of the event is undesirable has the strongest negative effect on changes in reputation for all firms and this effect is greater for firms with higher CSP.

Figure 1 below provides an overview of the proposed relationships between CI, CSP and reputation.

- Figure 1 -

\section{Methodology}

Data sample and data coding 
Our sample consists of Fortune Magazine's 'World's Most Admired Companies' (WMAC) survey. Fortune Magazine has conducted the WMAC survey every year since 1983 making it the most comprehensive longitudinal dataset of organizational reputation (Brammer and Millington, 2004; Brammer and Pavelin, 2005; Love and Kraatz, 2017). WMAC surveys top executives and directors from eligible companies, along with financial insiders who cover these companies, to identify those which enjoy the strongest reputation. In the WMAC survey, each company is rated relative to its competitors on nine key performance attributes: quality of management; quality of products or services; innovativeness; ability to attract, develop, and keep talented people; quality of marketing, long-term investment value; financial soundness; use of corporate assets; and community and environmental responsibility. An 11-point scale is used on each attribute $(0=$ poor, $10=$ excellent $)$. We use the overall reputation score which is determined through an average of the individual attributes (see also Brammer and Pavelin, 2006; Love and Kraatz, 2017). We extracted data on reputation ratings across eight annual surveys - from 2005 until 2012 - to develop a longitudinal assessment that reflects changes in reputation over time. This yielded a total of 3,696 company-years, or an average of 462 companies per survey.

Data on CI was collected and coded from ASSET4, a panel dataset compiled by Thomson Reuters which has been used in the past to analyse the effects of CSR and CI (c.f. Cheng, Ioannou and Serafeim, 2014). Using media reports, Thomson Reuters ASSET4 identifies the presence of events of CI and classifies these events into over thirty categories (e.g. 'intellectual property', 'anti-competition', 'human rights', 'product recalls'). To validate the ASSET4 dataset (Flammer, 2013), we conducted our own media searches via the LexisNexis search directory which, draws data from a wider range of reliable sources, i.e. both media press (e.g. Wall Street Journal, Financial Times) and corporate communications sources. We restricted the search to only identify CI events reported between 2004 and 2011 (one year 
prior to reputation scores) and associated with the organizations present in the WMAC survey. Following the validation process (1) CI events which had been counted into multiple event categories were recoded into a single event classification; and (2) observations of media reporting of CI events not already included in the ASSET4 dataset were added to update our database. This resulted in a total of 3,844 confirmed CI events. Since our sample is defined by the company-years for which we have at least two years of continuous reputation data (to measure year-on-year changes in reputation) and knowledge of a CI event or absence of a CI event, the final dataset contains a total of 1,518 company-year observations.

\section{Dependent variable: Changes in organizational reputation}

Our dependent variable is year-on-year changes in organizational reputation. The dependent variable measures whether there are any changes in organizational reputation scores from one year to another.

\section{Independent variable: $C I$ and CI situational characteristics ${ }^{1}$}

According to previous studies (e.g. Alexander, 1999; Karpoff and Lott 1993) CI results in damage to organizational reputation. In order to examine HI, we construct a measure ANY_EVENT - which measures the presence of at least one event of CI for each companyyear, enabling us to explore the relationship between CI and subsequent changes in reputation.

Next, we examine the individual and combined effect of situational characteristics of CI on changes in organizational reputation scores. 'CULPABILITY' measures whether the firm is found to have caused a CI event (Lange and Washburn, 2012); i.e. the firm is found responsible by a court ruling. When a company was found legally guilty of a CI event, the

\footnotetext{
${ }^{1}$ We lag our independent variables by one year relative to our dependent variable so that the information being used by stakeholders when updating their reputational assessments is reflected in our modelling structure.
} 
dichotomous variable noted culpability (' 1 ') and no legal culpability otherwise ('0'). The variable 'CULPABILITY” therefore counts the cumulative number of times where culpability was noted ' 1 ' for a company in a given year.

'NON-COMPLICITY' measures the presence of incidents involving victimized groups of stakeholders likely to be seen as non-complicit and who evoke increased sympathy from the general stakeholder pool (Lange and Washburn, 2012; Shaver, 1985) such as: (1) children, (2) the elderly, (3) individuals with long-term significant health issues, (4) pregnant women, (5) individuals who are significantly economically disadvantaged and (6) the disabled. When a company was perceived to harm a non-complicit group, NON-COMPLICITY took the value of ' 1 ' and ' 0 ' otherwise. 'NON-COMPLICITY" counts the cumulative number of times where a company was noted ' 1 ' in association with harming non-complicit groups in a given year.

Finally, 'EFFECT_UNDESIRABILITY' is a continuous variable which measures when CI events provoke reflexive judgments potentially leading to assessors approving or disapproving of firm behavior (see also Kim and Cameron, 2011; Lange and Washburn, 2012). Since stakeholders rarely experience events first-hand, they generally rely on 'infomediaries' to communicate information about CI (Deephouse and Heugens, 2009). The frequency with which certain words are used in business press is expected to have an impact on organizational assessors' perceptions of the firm (Carroll and McCombs, 2003). To measure CI effect undesirability, we used the Linguistic Inquiry and Word Count software (LIWC). LIWC is used due to its ability to measure the extent to which a body of text contains particular key words; this software codes words and phrases using underlying dictionaries developed in psychology and linguistics research (see Tausczik and Pennebaker, 2010 for more details). Using LIWC, we searched in the content of the media reports for the percentage of words that pertained to negative emotional responses; the categories of key words we were interested in were 'sadness' and 'anger' (Choi and Lin, 2009). We generated our overall measure of 
'EFFECT_UNDESIRABILITY' by multiplying the cumulative percentage of the articles expressing these emotional responses by the overall volume of media coverage (measured by the total word count of media articles relating to instances of CI per company-year) (see Appendix 1 for an overview of the step-by-step process used to collect data on, and measure, the three situational characteristics variables).

On the combined effect of CI situational characteristics we use 'CULPABILITY X NON_COMPLICITY' as a proxy that captures when the firm is found culpable for an event where the affected party is perceived as non-complicit; 'EFFECT_UNDESIRABILITY $\mathrm{X}$ NON_COMPLICITY' measures the presence of observed effect undesirability when the affected party is perceived as non-complicit; and 'EFFECT_UNDESIRABILITY $\mathrm{X}$ CULPABILITY' measures the presence of observed effect undesirability and culpability. Finally, CULPABILITY $\mathrm{X} \quad$ 'EFFECT_UNDESIRABILITY $\mathrm{X}$ NON_COMPLICITY' ${ }^{2}$ measures the effect on changes in reputation when all three situational characteristics are present.

\section{Moderator: CSP}

We construct our CSP measure by using detailed social performance data from Thomson Reuters' Datastream. These ratings are available for over 7,000 companies since 2002. CSP is measured for each company-year. In line with previous studies (see Walker et al., 2010) we use the overall CSP score which is calculated by using four equally weighed dimensions, namely: workforce, human rights, community and product responsibility (Thomson Reuters, 2018). SOC_SCORE is a continuous variable ranging from 0 to 100 , with a higher value representing higher firm commitment to CSP. We assumed that CI effects predict changes in

\footnotetext{
${ }^{2}$ The combined variable is a continuous variable which measures the relationship between 'EFFECT_UNDESIRABILITY' and changes in reputation scores when firms were found culpable and non-complicit.
} 
reputational scores differently for firms which are ranked in the top (Top CSP), second (High CSP), third (Low CSP) or bottom quartiles of CSP evaluations (Bottom CSP).

\section{Control variables}

Larger firms tend to be more visible to reputational assessors (Walker, Zhang and $\mathrm{Ni}, 2018$ ); FIRM_SIZE is measured as the natural logarithm of the value of total assets. Since previous studies have linked product range to firm reputation (Fombrun and Shanley, 1990), this study controls for R\&D INTENSITY (RDASS), measured as the ratio of R\&D expenditures to total assets. Further, strong financial performance such as high levels of return on assets (ROA) are linked to healthy corporate strategizing, good management and efficient resource allocation, all of which have been associated with a good reputation (Fombrun and Shanley, 1990; Roberts and Dowling, 2002; Brammer and Pavelin, 2006); ROA is measured as the ratio of pre-tax profits to total assets. In turn, the leverage ratio, which controls for the degree of financial flexibility, may negatively influence reputation as it may be perceived as a burden upon future returns (Walker et al., 2018); LEVERAGE is measured by the ratio of total debt to total assets. This data was collected from Thomson Reuters Datastream and measured for each companyyear.

In line with previous studies (Brammer and Pavelin, 2006), we control for how well companies score in areas associated with reputational performance. Environmental performance (ENV_SCORE) measures the degree to which a company uses best management practices to avoid environmental risks and capitalise on environmental opportunities to increase long term shareholder value. Corporate governance performance (CGV_SCORE), in turn, measures the proportion of equity held by long-term institutional investor groups, such as pension funds, insurance companies and life assurors (see also Brammer and Pavelin, 2006; 
Johnson and Greening, 1999; Ryan and Schneider, 2002) ${ }^{3}$. The rationale here is that a strong presence of institutional investors may signal that the activity of the firm is well monitored. These variables are available in Datastream where they are measured on a scale from 0 to 100 with a higher value representing better performance in each area (Thomson Reuters, 2018).

\section{Data analysis}

In line with previous studies on organizational reputation (notably, Brammer and Millington, 2004; Brammer and Pavelin, 2006), this study employs multiple linear regression analysis. This statistical method was applied due to the characteristics of the dependent variable, which is a continuous, scalar variable; and the mix of both categorical and continuous independent variables which can either positively or negatively influence an organization's reputation scores. We estimate a linear regression model with change in organizational reputation as the dependent variable. Regression coefficients in linear regression represent the mean change in the dependent variable (changes in reputation) for every one unit of change in the independent variables, while holding other predictors in the model constant.

Given that our sample is a panel data structure, we conducted econometric tests to ensure the validity of our linear regression models (Table 1). To alleviate the impact of outliers, we censored all continuous variables at the $1 \%$ and $99 \%$ tail. We used the Durbin-Watson statistic test to detect the presence of autocorrelation in the residuals. The Durbin-Watson test statistic value was 2.080 which means that our regression model does not violate the assumption of instance independence. Table 1 reports the summary statistics of firm-level variables. The average firm size is 9.15 billion dollars $^{4}$. The average leverage ratio is about $21 \%$. Sampled firms have an average R\&D investment of under $2 \%$, with a mean ROA of just

\footnotetext{
${ }^{3}$ We keep SOC_SCORE as a control because we can measure, within a category of CSP, whether the magnitude of the effect has an impact on changes in organizational reputation.

${ }^{4}$ We calculate the total assets in billion dollars based on the mean log (total assets).
} 
under $7 \%$. Social, environmental and corporate governance performance average scores are of $56 / 100,51 / 100$ and 77/100 respectively. Overall, the organizations in our sample are large firms with growth opportunities and significant resources. As predicted, the t-test and MannWhitney test show statistically significant differences between top social performers and other firms, indicating that there are key firm characteristics which influence the assessment of CI on reputation changes. VIFs range between 1.083 and 2.731, suggesting no serious problems of multicollinearity.

\section{Results}

We report the results for all firms as well as for individual sub-samples (Top CSP, High CSP, Low CSP, Bottom CSP) in each regression model. Model 1 in Table 2 presents the baseline model. In line with previous studies (see Walker et al., 2018), larger, better financially performing and less leveraged companies benefit from positive changes in their reputations. In the short term, higher R\&D intensity can mean that firms are exploring new resources and investment opportunities (and thus, incurring higher costs) rather than exploiting extant competitive advantages; this may explain why the coefficients of $R \& D$ intensity are negative for companies with high CSP and positive for those with bottom CSP. Environmental performance is related to positive (negative) changes in reputation for firms with lower (higher) levels of CSP; environmental performance could be perceived as an unnecessary cost for firms with relatively higher CSP scores (Walley and Whitehead, 1994), driving down the benefits associated with the investment. In turn, the reason why governance performance was found to negatively impact firms with low CSP may be that assessors become sceptical of companies with low social performance and even perceive their governance efforts as insincere.

\section{H1: Broad categories of CI will not affect reputation change}


Contrary to previous studies (e.g. Alexander, 1999), the occurrence of CI alone does not evoke reputation penalties (and thus we fail to reject the null $\mathrm{H} 1$ ). In fact, results point to a positive relationship between CI and reputation enhancements with the exception of firms with low CSP where we did find some (non-significant) evidence of a negative reputational effect (Model 2 in Table 2). Our interpretation stands, in that, without examining the situational characteristics of CI events, we cannot simply take for granted that events are considered irresponsible by reputational assessors.

\section{- Table 2 -}

H2 (a, b, c): CI with one situational characteristic will affect reputation change

When studying the situational characteristics of CI events (Model 3 in Table 3), we found that culpability is broadly associated with negative changes in reputation $(-0.123$, at $10 \%$ level), non-complicity does not have a significant effect (-0.027, n.s.), and effect undesirability tends to be associated with positive reputation change (0.007, at $1 \%$ level). When CSP is considered, there is variation in some of these results. Overall, we find reasonably strong evidence in support of $\mathrm{H} 2 \mathrm{a}$, in that firms that are found culpable of $\mathrm{CI}$ experience negative changes in reputation, with the effect being strongest for firms with the highest prior CSP $(-0.318$, at $1 \%$ level). Surprisingly, we found that affected party non-complicity (H2b) only affects the reputation of firms with the weakest prior CSP (-0.645, at $1 \%$ level), - suggesting that such events are likely to match stakeholders' low expectations, who respond more strongly to the confirmatory evidence by enacting reputational penalties. Thus, being scored as a poor social performer may mean that a firm is perceived to behave irresponsibly even without substantive factual evidence (i.e. corporate culpability). In relation to $\mathrm{H} 2 \mathrm{c}$, we find more mixed evidence with effect undesirability being associated with small but statistically significant improvements in organizational reputations for top CSP firms (0.015, at $1 \%$ level). Effect undesirability, as represented by media accounts of CI, may not only elicit social assessors to dismiss events that 
contradict current perceptions (Ravasi et al., 2018), but inspire some evaluators to counteract unjust claims of CI by strengthening reputation evaluations.

- Table 3 -

$H 3(a, b, c): C I$ with two situational characteristics will have a stronger effect on reputation change

In line with $\mathrm{H} 3 \mathrm{a}$, we found that firms with higher CSP evoke stronger perceptions of organizational hypocrisy when perceived culpable for CI events which are also associated with harming non-complicit parties (-0.470, at 1\% level) (Model 4 in Table 4). In turn, the presence of effect undesirability reduces the negative relationship between CI and reputation. For instance, when the CI event is undesirable, and the affected party is non-complicit ( $\mathrm{H} 3 \mathrm{~b})$, bottom CSP firms are significantly penalized but the effect is weaker compared to when undesirability was absent $(-0.031$, at $1 \%$ level) (Model 5 in Table 4). Similarly, when culpability is associated with an undesirable CI event (H3c), firms with top CSP are still penalized by organizational assessors but the negative reputational effect is weaker compared to when culpability alone was considered (-0.014, at $1 \%$ level) (Model 6 in Table 4). Overall, we find that, rather than their being complementarity effects of additional CI characteristics (Lange and Washburn, 2012), instead, our results suggest that CI characteristics are interpreted in the context of prior expectations. However, these results also suggest that effect undesirability reduces the reputation penalties of CI. One interpretation of this result, is that increased effect undesirability, reflected in the frequency and tone of media scrutiny, provides the explicit feedback necessary to motivate organizations to allocate resources to mitigate reputation damage through reputation management. Our interpretation aligns with extant research, which suggest that media scrutiny is a central feedback mechanism between stakeholders and the organization (Pfarrer, Decelles, Smith and Taylor, 2008; Zyglidopoulos, Georgiadis, Carroll and Siegel, 2012). 


\section{- Table 4 -}

H4: CI with all three situational characteristics will have the strongest effect on reputation change

When the firm is found culpable, when the affected party is non-complicit and when CI is undesirable (Model 7 in Table 5), top social performers suffer reputation penalties (-0.019 at $1 \%$ level) whereas the effect becomes weaker at lower levels of CSP. Results broadly support H4. This said, we did not find support for the assumption that the combination of all three characteristics has the strongest effect on reputation change (Lange and Washburn, 2012). Most notable perhaps is that, the largest effect in our results appears when we examine the effect of culpability for top CSP and the effect of non-complicity for bottom CSP. This evidence reflects our proposition that social evaluations of CI are constructed in in relation to stakeholders' prior expectations of the firm. In contrast to prior theorizing (Lange and Washburn, 2012), we do not find evidence of the complementarity effect of multiple situational characteristics of CI. Instead we find further support for the 'scope-severity paradox' perspective, where, in social psychology, empirical research often finds that harmful behavior is perceived to be less severe by observers than less harmful behavior (see Nordgren and Morris McDonnell, 2011). An interpretation of this result is that CI with significant evidence of corporate culpability, affected party non-complicity and effect undesirability may most strongly motivate organizations accused of CI to engage in reparative reputation management (Pfarrer et al., 2008; Zyglidopoulos et al., 2012). Reparation efforts, such as increasing CSR activities and philanthropy, may counteract the negative effects of CI. We elaborate further on this and other findings in our discussion. ${ }^{5}$

\footnotetext{
${ }^{5}$ Similar to other studies on CI (Walker et al., 2018), we have an unbalanced panel dataset whereby we have varying numbers of years for all the units of observation (companies in our case). We therefore also checked whether the frequency with which a company appears in the dataset may have an impact on the robustness of our results. We ran various reiterations of the regression models where we excluded firms that appeared with a relatively larger number of observations. The results hold.
} 


\section{- Table 5 -}

\section{Discussion}

In this paper, we explored the relationship between CI, CSP and changes in organizational reputation. We made three main contributions. First, we examined when $\mathrm{CI}$ influences organizational reputations in the context of variations in CSP. We found that CI events, broadly speaking, do not significantly alter organizational reputations. This finding is particularly concerning, as social sanctions are understood to be a key mechanism by which organizations are discouraged from behaving irresponsibly (Aguilera et al, 2007; Brammer et al., 2012). Instead, we find that reputations are relatively stable in light of CI. Stakeholders generally dismiss CI events that contradict current perceptions (Ravasi et al., 2018). Therefore, a central mechanism assumed to regulate $\mathrm{CI}$, is potentially much weaker than previously understood.

Second, by combining attribution theory with expectancy violations theory we explore how organizational reputations change in light of CI. Contrary to previous attribution studies (Lange and Washburn, 2012), we do not find substantive evidence of the complementarity impact of CI situational characteristics. Specifically, we do not find that multiple CI situational characteristics outlined by attribution theory (Lange and Washburn, 2012), consistently lead to greater perceptions of CI (Nordgren and Morris McDonnell, 2011). Instead, our results suggest that the situational characteristics of CI are evaluated principally against stakeholder expectations of the firm accused. In particular, CSP appears to be an important contextual consideration in shaping organizational assessors' expectations and subsequent evaluations. To date, the attribution literature largely focuses on the characteristics of events salient to social evaluators. We enrich the attribution theory perspective by highlighting the important role that stakeholders' prior expectations play in shaping social evaluations.

Third, we explored for whom CI influences organizational reputation. Consistent with extant research in CSR (Brammer and Pavelin, 2005; Ducassy, 2013; Godfrey, 2005), we find 
support for the perspective that stakeholders afford firms with positive associations 'the benefit of the doubt' when accused of CI. However, when culpability for CI is confirmed by a court of law, top social performing firms are penalized with the additional social sanction of reputation penalties further to any actions enforced by the courts. We proposed that, in such circumstances, the best social performers provoke a sense of betrayal, leading stakeholders to attribute hypocrisy and revise-down their reputation assessments. In turn, without courtdetermined culpability for CI, stakeholders tend to perceive top CSP firms as innocent until proven guilty. This paper contributes to attribution theory by identifying the important role played by litigation in reinforcing social evaluations.

Additionally, we found that firms with low social performance incurred the most substantial reputation penalties in circumstances where CI was associated with harming noncomplicit stakeholder groups, without evidence of effect undesirability or corporate culpability. We explain that, in the event a firm with low CSP is associated with harming noncomplicit stakeholders, yet is not penalized by litigation, social evaluations appear to step-in to assume a regulatory role by revising-down organizational reputation. These findings contribute to our understanding of social regulation (Campbell, 2007) by highlighting that social evaluations and sanctions are highly context dependent. In so doing, we identify a "fine line dividing the tendency of audiences to disregard events that contradict current perceptions and their willingness to reconsider their judgments and form new and different evaluations of organizations" (Ravasi et al., 2018: 585). Namely, the important role that legal verdicts and prior stakeholder expectations play in motivating social revaluations.

From a policy perspective, our research highlights the infrequency with which CI has reputational impacts. Our findings challenge the CSR literature which has argued that social sanctions perform a 'quasi-regulatory' role by influencing organizations to behave responsibly (Aguilera et al, 2007; Brammer et al., 2012; Campbell, 2007). The social regulation perspective 
holds that firms are encouraged to behave responsibly in order to avoid the associated reputational costs of being considered irresponsible. Whilst we do not entirely disagree with this rationale, our study finds that stakeholders only penalize certain firms, in certain circumstances. Most notably, we find that the 'quasi-regulatory' mechanism performed by social evaluations acts well when organizations are perceived to be hypocritical and when legal penalties are perceived inadequate or non-existent. In turn, social sanction may only play a marginal role in discouraging irresponsible behavior for firms which are neither ranked as top nor as bottom social performers. In light of these results, we argue that more appropriate regulation can promote better corporate social performance as well as discourage irresponsibility for these firms.

\section{Limitations and future research directions}

A central finding of our research is that social sanctions for CI are less frequent and severe than previously assumed. Therefore, the overall regulatory effect of reputation penalties appears to be a much weaker deterrent of CI than is currently held (Aguilera et al, 2007; Brammer et al., 2012). A central question arises from this result: 'why are reputations generally stable in light of corporate irresponsibility?'. This paper utilizes WMAC data, therefore we capture the perceptions of a particular set of organizational stakeholders, namely managers and market analysts. Future research should explore social sanctions of other stakeholder groups, such as employees or customers.

Similar to prior research on reputational effects (Flanagan and O'Shaughnessy, 2005; Love and Kraatz, 2017), we collected annual data on reputations. However, it may be that reputation effects take place within a year, and by the time the survey is conducted again, the reputation of the firm has bounced back. One way of exploring this is to classify CI events according to when specifically, they take place in the year, i.e. an early/late dichotomy would 
be useful to further examine if reputational effects are more intense for events close to the survey window and largely forgotten later on (Mena, Rintamäki, Fleming and Spicer, 2016).

Finally, in line with prior reputation and irresponsibility studies (De Cremer, van Dick, Tenbrunsel, Pillutla and Murnighan, 2011; Okhmatovskiy and Shin, 2018; West, Hillenbrand, Money, Ghobadian and Ireland, 2016), we point to the importance of examining the context in which social evaluations take place. Future research should consider other contextual factors which may inform social evaluations, such as the celebrity status of the firm or the management responses to reputation threats.

\section{Conclusion}

This study provided a detailed examination of the relationship between corporate irresponsibility $(\mathrm{CI})$, corporate social performance (CSP) and organizational reputation. We found that organizational reputation is largely stable in light of CI. However, firms with enhanced CSP may provoke perceptions of hypocrisy and are subject to social sanction when culpability for CI is verified by litigation. Additionally, we find low CSP firms associated with harming vulnerable, non-complicit stakeholder groups and not penalized by litigation experience reputation decline as social sanctions step-in to fill the regulatory space. 


\section{References}

Aguilera, R.V., D. E. Rupp, C. A. Williams and J. Ganapathi, (2007). 'Putting the S back in corporate social responsibility: A multilevel theory of social change in organizations'. Academy of Management Review, 32, pp. 836-863.

Alicke, M. D. (2000). 'Culpable control and the psychology of blame'. Psychological Bulletin, 126, pp. 556574.

Alexander, C. R. (1999). 'On the nature of the reputational penalty for corporate crime: Evidence'. Journal of Law and Economics, 42, pp. 489-526.

Antonetti, P. and M. Anesa (2017). 'Consumer reactions to corporate tax strategies. The role of political ideology’. Journal of Business Research, 74, 1-10.

Antonetti, P. and S. Maklan (2016). 'Social identification and corporate irresponsibility: A model of stakeholder punitive intentions'. British Journal of Management, 27, pp. 583-605.

Appiah, K. A. (2009). 'Experiments in ethics'. Cambridge, MA: Harvard University Press.

Bailey, A. A. and C. M. Bonifield (2010). 'Broken (promotional) promises: The impact of firm reputation and blame'. Journal of Marketing Communications, 16, pp. 287-306.

Barnett, M. L. and R. M. Salomon (2012). 'Does it pay to be really good? addressing the shape of the relationship between social and financial performance'. Strategic Management Journal, 33, pp. 13041320 .

Bitektine, A. (2011). 'Toward a theory of social judgments of organizations: The case of legitimacy, reputation, and status'. Academy of Management Review, 36, pp. 151-179.

Brammer, S. J. and A. Millington (2004). 'The development of corporate charitable contributions in the UK: A stakeholder analysis'. Journal of Management Studies, 41, pp. 1411-1434.

Brammer, S. J. and S. Pavelin (2005). 'Corporate reputation and an insurance motivation for corporate social investment'. The Journal of Corporate Citizenship, 20, pp. 39-51.

Brammer, S. J. and S. Pavelin (2006). 'Corporate reputation and social performance: The importance of fit'. Journal of Management Studies, 43, pp. 435-455.

Brammer, S. J., G. Jackson and D. Matten (2012). 'Corporate social responsibility and institutional theory: New perspectives on private governance.' Socio-Economic Review, 10, pp. 3-28.

Bundy, J. and M. D. Pfarrer (2015). 'A burden of responsibility: The role of social approval at the onset of a crisis'. Academy of Management Review, 40, pp. 345-369.

Burgoon, J. K. (1978). 'A communication model of personal space violations: Explication and an initial test'. Human Communication Research, 4, pp. 129-142.

Campbell, J. L. (2007). 'Why would corporations behave in socially responsible ways? An institutional theory of corporate social responsibility'. Academy of Management Review, 32, pp. 946-967.

Carlos, W. C. and B. W. Lewis (2018). 'Strategic Silence: Withholding certification status as a hypocrisy avoidance tactic'. Administrative Science Quarterly, 63, pp. 130-169.

Carroll, C. E. and M. McCombs (2003). 'Agenda-setting effects of business news on the public's images and opinions about major corporations'. Corporate Reputation Review, 6, pp. 36-46.

Choi, Y. and Y. H. Lin (2009). 'Consumer responses to Mattel product recalls posted on online bulletin boards: Exploring two types of emotion'. Journal of Public Relations Research, 21, pp. 198-207.

Claeys, A.S., V. Cauberghe and P. Vyncke (2010). Restoring reputations in times of crisis: An experimental study of the Situational Crisis Communication Theory and the moderating effects of locus of control. Public Relations Review. 36, pp. 256-262.

De Cremer, D., R. van Dick, A. Tenbrunsel, M. Pillutla and K. J. Murnighan (2011). 'Understanding ethical behavior and decision making in management: A behavioural business ethics approach'. British Journal of Management, 22, pp. S1-S4.

De Jong, M. D. T. and M. van der Meer (2017). 'How does it fit? Exploring the congruence between organizations and their corporate social responsibility (CSR) activities'. Journal of Business Ethics, 143, pp. 71-83.

Deephouse, D. and P. Heugens (2009). 'Linking social issues to organizational impact: The role of infomediaries and the infomediary process'. Journal of Business Ethics, 86, pp. 541-553. 
Donaldson, T. and T. Dunfee (1999). 'Ties that bind: A social contracts approach to business ethics'. Boston: Harvard University Press.

Ducassy, I. (2013). 'Does corporate social responsibility pay off in times of crisis? An alternate perspective on the relationship between financial and corporate social performance'. Corporate Social Responsibility and Environmental Management, 20, pp. 157-167.

Fiske, S. T. and S. E. Taylor (1991). 'Social cognition'. (2nd ed.) New York: McGraw-Hill.

Flanagan, D. J. and K. C. O'Shaughnessy (2005). 'The effect of layoffs on firm reputation'. Journal of Management, 31, pp. 445-463.

Fombrun, C. J. and V. Rindova (1996). 'Who's tops and who decides? The social construction of corporate reputations', New York University, Stern School of Business, Working Paper.

Fombrun, C. and M. Shanley (1990). 'What's in a name? Reputation building and corporate strategy'. Academy of Management Journal, 33, pp. 233-258.

Flammer, C. (2013). 'Corporate social responsibility and shareholder reaction: The environmental awareness of investors'. Academy of Management Journal, 56, pp. 758-781.

Godfrey, P. (2005). 'The relationship between community investments and shareholder wealth'. Academy of Management Review, 30, pp. 777-798.

Grappi, S., S. Romani and R. P. Bagozzi (2013). 'Consumer response to corporate irresponsible behavior: The role of moral emotions and virtues'. Journal of Business Research, 66, pp. 1814-1821.

Haidt, J. and F. Bjorklund (2008). 'Social intuitionists answer six questions about morality'. In W. SinnottArmstrong (Eds.), Moral psychology. Volume 2: The cognitive science of morality, Cambridge, MA: MIT Press, pp. 181-217.

He, X., J. Pittman and O. M. Rui. (2016). 'Reputational implications for partners after a major audit failure: Evidence from China'. Journal of Business Ethics, 138, pp. 703-722.

Janney, J. J. and S. Gove (2011). 'Reputation and Corporate social responsibility aberrations, trends, and hypocrisy: Reactions to firm choices in the stock option backdating scandal'. Journal of Management Studies, 48, pp. 1562-1585.

Janssen, C., S. Sen and C. B. Bhattacharya (2015). 'Corporate crises in the age of corporate social responsibility'. Business Horizons, 58, pp. 183-192.

Johnson, R. A. and D. W. Greening (1999). 'The effects of corporate governance and institutional ownership types on corporate social performance'. Academy of Management Journal, 42, pp. 564-576.

Kaplan, S., J. C. McElroy, S. P. Ravenscroft and C. Shrader (2007). 'Moral judgements and causal attributions: Consequences of earnings management. Journal of Business Ethics, 74, pp. 149-164.

Karpoff, J. M. and J. R. Jr. Lott (1993). 'The reputational penalty firms bear from committing criminal fraud'. Journal of Law and Economics, 36, pp. 757-802.

Karpoff, J. M., J. R. Jr. Lott and E. W. Wehrly (2005). 'The reputational penalties for environmental violations: Empirical evidence'. Journal of Law and Economics, 48, pp. 653-675.

Karpoff, J. M., S. Lee and G. Martin (2008). 'The cost to firms of cooking the books'. Journal of Financial and Quantitative Analysis, 43, pp. 581-611.

Kelley, H. H. (1967). 'Attribution theory in social psychology'. In D. Levine (Ed.), Nebraska symposium on motivation (Vol. 15, pp. 192-240). Lincoln: University of Nebraska Press.

Kelley, H. H. (1972). 'Attribution in social interaction. In E. E. Jones, D. E. Kanouse, H. H. Kelley, R. E. Nisbett, S. Valins and B Weiner (Eds.) Attribution: Perceiving the causes of behavior, pp.1-26. Morristown, NJ: General Learning Press.

Kim, H. J. and G. T. Cameron (2011). 'Emotions matter in crisis: The role of anger and sadness in the publics' response to crisis news framing and corporate crisis response'. Communication Research, 38, pp. 826855.

Kim, S. (2014). 'What's worse in times of product-harm crisis? Negative corporate ability or negative CSR reputation?' Journal of Business Ethics, 123, pp. 157-170.

Kölbel, J. F., T. Busch and L. M. Jancso (2017). 'How media coverage of corporate social irresponsibility increases financial risk'. Strategic Management Journal, 38, pp. 2266-2284.

Lange, D. and N. T. Washburn (2012). 'Understanding attributions of corporate social irresponsibility'. Academy of Management Review, 37, pp. 300-326. 
Laufer, D. and T. W. Coombs (2006). 'How should a company respond to a product harm crisis? The role of corporate reputation and consumer-based cues'. Business Horizons, 49, pp. 379-385.

Leavitt, K., L. Zhu and K. Aquino (2016). 'Good without knowing it: Subtle contextual cues can activate moral identity and reshape moral intuition'. Journal of Business Ethics, 137, pp. 785-800.

Lessig, L. (2013). 'Foreword: “Institutional Corruption” defined'. The Journal of Law, Medicine \& Ethics, 41, pp. $553-555$.

Lin, H., S. Zeng, L. Wang, H. Zou and H. Ma (2016). 'How does environmental irresponsibility impair corporate reputation?' Corporate Social Responsibility and Environmental Management, 23, pp. 413-423.

Loewenstein, G. (1996). 'Out of control: Visceral influences on behavior'. Organizational Behavior and Human Decision Processes, 65, pp. 272-292.

Love, E. G. and M. S. Kraatz (2009). 'Character, conformity, or the bottom line? How and why downsizing affected corporate reputation'. Academy of Management Journal, 52, pp. 314-335.

Love, E. G. and M. S. Kraatz (2017). 'Failed stakeholder exchanges and corporate reputation: The case of earnings misses'. Academy of Management Journal, 60, pp. 880-903.

Love, E. G., J. Lim and M. Bednar (2017). 'The face of the firm: The influence of CEOs on corporate reputation'. Academy of Management Journal, 60, pp. 1462-1481.

Margolis, J. D. and J. P. Walsh (2003). 'Misery loves companies: Rethinking social initiatives by business'. Administrative Science Quarterly, 38, pp. 268-305.

Mena, S., J. Rintamäki, P. Fleming and A. Spicer (2016). 'On the forgetting of corporate irresponsibility'. Academy of Management Review, 41, pp. 720-738.

Minor, D. and J. Morgan (2011). 'CSR as reputation insurance: Primum non Nocere'. California Management Review, 53, pp. 40-59.

Mishina, Y., E. S. Block and M. J. Mannor (2012). 'The path dependence of organizational reputation: How social judgment influences assessments of capability and character'. Strategic Management Journal, 33, pp. 459- 477.

Nordgren, L. F. and M. H. Morris McDonnell (2011). 'The scope-severity paradox: Why doing more harm is judged to be less harmful'. Social Psychological and Personality Science, 2, pp. 97-102.

Oikonomou, I., C. Brooks and S. Pavelin (2014). 'The financial effects of uniform and mixed corporate social performance'. Journal of Management Studies, 51, pp. 898-925.

Okhmatovskiy, I. and D. Shin (2018). 'Changing corporate governance in response to negative media events'. British Journal of Management, 30, pp. 169-187.

Ormiston, M. E. and E. M. Wong (2013). 'License to ill: The effects of corporate social responsibility and CEO moral identity on corporate social irresponsibility’. Personnel Psychology, 66, pp. 861-893.

Pfarrer, M. D., K. A. Decelles, K. G. Smith and S. M. Taylor (2008). 'After the fall: Reintegrating the corrupt organization'. Academy of Management Review, 33, pp. 730-749.

Price, J. M. and W. Sun (2017). 'Doing good and doing bad: The impact of corporate social responsibility and irresponsibility on firm performance'. Journal of Business Research, 80, pp. 82-97.

Ravasi, D., V. Rindova., M. Etter and J. Cornelissen. (2018). 'The formation of organizational reputation'. Academy of Management Annals, 12, pp. 574-599.

Reinecke, J. and S. Ansari (2016). 'Taming wicked problems: The role of framing in the construction of corporate social responsibility'. Journal of Management Studies, 53, pp. 299-329.

Rhee, M. and P. R. Haunschild (2006). 'The liability of good reputation: A study of product recalls in the U.S. automobile industry'. Organization Science, 17, pp. 101-117.

Rhee, M. and M. E. Valdez (2009). 'Contextual factors surrounding reputation damage with potential implications for reputation repair'. Academy of Management Review, 34, pp. 146-168.

Rim, H., Y. E. Park and D. Song (2018). 'Watch out when expectancy is violated: An experiment of inconsistent CSR message cueing'. Journal of marketing Communications, DOI: https://doi.org/10.1080/13527266.2018.1523216

Roberts, P. W. and G. R. Dowling (2002). 'Corporate reputation and sustained superior financial performance'. Strategic Management Journal, 23, pp. 1077-1093.

Ryan, L. V. and M. Schneider (2002). 'The antecedents of institutional investor activism'. Academy of Management Review, 27, pp. 554-573. 
Shaver, K. G. (1985). 'The attribution of blame: Causality, responsibility, and blameworthiness'. New York: Springer.

Shiu, Y. M. (2017). 'Does engagement in corporate social responsibility provide strategic insurance-like effects?'. Strategic Management Journal, 38, pp. 455-470.

Sjovall, A. M. and Talk, A. C. (2004). 'From actions to impressions: Cognitive attribution theory and the formation of corporate reputation'. Corporate Reputation Review, 7, pp. 269-281.

Skilton, P. F. and J. M. Purdy (2017). 'Authenticity, power, and pluralism: A framework for understanding stakeholder critical reviews of corporate social responsibility activities'. Business Ethics Quarterly. 27, pp. 99-123.

Sweetin, V. H., L. L. Knowles, J. H. Summey and K. S. McQueen (2013). 'Willingness-to-punish the corporate brand for corporate social irresponsibility'. Journal of Business Research, 66, pp. 1822-1830.

Tausczik, Y. R. and J. W. Pennebaker (2010). 'The psychological meaning of words: LIWC and computerized text analysis methods'. Journal of Language and Social Psychology, 29, pp. 24-54.

Tucker, L. and T. C. Melewar (2005). Corporate Reputation and Crisis Management: The Threat and Manageability of Anti-corporatism. Corporate Reputation Review. 7, pp. 377-387.

Vanhamme, J. and B. Grobben (2009). "'Too Good to be True!". The effectiveness of CSR history in countering negative publicity'. Journal of Business Ethics, 85, pp. 273-283.

Voliotis, S., P. A. Vlachos and O. Epitropaki (2016). 'Perception-induced effects of corporate social irresponsibility (CSiR) for stereotypical and admired firms'. Frontiers in Psychology, 7, 970-976.

Wagner, T., R. J. Lutz and B. A. Weitz (2009). 'Corporate hypocrisy: Overcoming the threat of inconsistent corporate social responsibility perceptions'. Journal of Marketing, 73, pp. 77-91.

Walker, K. A. (2010). 'A systematic review of the corporate reputation literature: Definition, measurement, and theory'. Corporate Reputation Review, 12, pp. 357-387.

Walker, M., B. Heere, M. M. Parent and D. Drane (2010). 'Social responsibility and the Olympic Games: The mediating role of consumer attributions'. Journal of Business Ethics, 93, pp. 1-22.

Walker, K., Z. Zhang, Z. and N. Ni (2018). 'The mirror effect: Corporate social responsibility, corporate social irresponsibility and firm performance in coordinated market economies and liberal market economies'. British Journal of Management. DOI: https://doi.org/10.1111/1467-8551.12271.

Walley, N and B. Whitehead (1994). 'It's not easy being green'. Harvard Business Review, 72, pp. 46-52.

Wei, J. C., Z. Ouyang, Z. and H. P. Chen (2017). 'Well known or well liked? The effects of corporate reputation on firm value at the onset of a corporate crisis'. Strategic Management Journal, 38, pp. 2103-2120.

Weick, K. E., K. M. Sutcliffe and Obstfeld, D. (2005). 'Organizing and the process of sensemaking'. Organization Science, 16, pp. 327-451.

Weiner, B., S. Graham and C. Chandler (1982). 'Pity, anger, and guilt: An attributional analysis'. Personality and Social Psychology Bulletin, 8, pp. 226-232.

West, B., C. Hillenbrand, K. Money, A. Ghobadian and D. R. Ireland (2016). 'Exploring the impact of social axioms on firm reputation: A stakeholder perspective'. British Journal of Management, 27, pp. 249-270.

Yoon, Y., Z. Gürhan-Canli, Z. and N. Schwarz (2006). 'The effect of corporate social responsibility (CSR) activities on companies with bad reputations'. Journal of Consumer Psychology, 16, pp. 377-390.

Zavyalova, A., M. D. Pfarrer, R. K. Reger and T. D. Hubbard (2016). 'Reputation as a benefit and a burden? How stakeholders' organizational identification affects the role of reputation following a negative event'. Academy of Management Journal, 59, pp. 253-276.

Zyglidopoulos, S. C. (2001). 'The impact of accidents on firms' reputation for social performance'. Business \& Society, 40, pp. 416-432.

Zyglidopoulos, S. C., A. P. Georgiadis, C. E. Carroll and D. S. Siegel (2012). 'Does media attention drive corporate social responsibility?’. Journal of Business Research, 11, pp. 1622-1627. 